\title{
Optimization of gene delivery to HEK293T cells by microporation using a central composite design methodology
}

Madeira, C*.; Ribeiro, SC.; Turk, M.Z.; Cabral, J.M.S.

IBB-Institute for Biotechnology and Bioengineering, Centre for Biological and Chemical Engineering, Instituto Superior Técnico, Av. Rovisco Pais, 1049-001, Lisboa, Portugal

Section of the Journal: Animal Cell Technology

\begin{abstract}
Microporation is an efficient method for delivering plasmid DNA molecules into cultured cells. Herein, we present the optimization of gene delivery by microporation using a Central Composite Design methodology. It was given relevance not only to the transfection efficiency but also to the cell recovery. Different amounts of DNA (1 and 3 g) mainly affected cell viabilities and cell recoveries, which decrease from $93 \%$ to $76 \%$ and from $47 \%$ to $25 \%$ respectively, when higher DNA quantity is used. With this work we suggest an easy methodology to improve transfection of mammalian cells underlining the feasibility to achieve $60 \%$ of gene delivery efficiencies whilst recovering $50 \%$ of cells, with $90 \%$ of viability.
\end{abstract}

\section{Keywords}

Cell recovery; Central Composite Design; Gene delivery; Microporation; Plasmid DNA. 


\section{Introduction}

Gene electrotransfer has been a powerful tool to transfer DNA molecules into a large variety of prokaryotic and eukaryotic cells. However, there are still some problems urging to be solved such as low cell viabilities and low transfection efficiencies especially when using low DNA amounts. Most of published data has been obtained from conventional electroporation that usually relies on the use of high electrode surfaces areas requiring minimum volumes of 501 . Novel devices with different layouts have been recently developed and tested with several cell lines for diverse applications (see recent review (Lee et al. 2009)). Our study comprises the use of a microcapillary system with an electrode surface area of $0.33 \mathrm{~mm}^{2}$ and 101 chamber for cell suspension microporation (Kim et al. 2008). In most published work, transfection efficiency and cell viabilities are the only considered output values for electroporation optimization, which we consider that may mislead the process efficiency. In fact, high cell viabilities may be obtained even when few cells are recovered after being submitted to electric voltages. To our best knowledge few authors have published results regarding cell recovery and yield of transfection after electroporation of mammalian cells (Aluigi et al. 2006; Ferreira et al. 2008).

In this work a Central Composite Design (CCD) methodology was used as a valuable tool to assess the effect of several independent factors on HEK293T gene delivery efficiency by microporation. These cells are able to replicate appropriated plasmids (Wurm et al. 2003) and have been used in basic research and for production of virus and recombinant proteins (Pham et al. 2006). Moreover, microporation is a recent available and promising technology of gene transfer and taking into account the conditions that gave rise to higher percentages of cells expressing a reporter protein we have evaluated not only cellular viability but also cell recovery and transfection yield which constitutes new data regarding this methodology. Taken together, our results will certainly be very useful in gene delivery applications to mammalian cells. 


\section{Materials and methods}

Plasmid construction and purification

The plasmid pcDNA3.1 (Invitrogen, La Jolla, CA) encoding green fluorescent protein (GFP) reporter gene was constructed using standard cloning methods. This plasmid has a SV40 ori, therefore able to replicate in mammalian cell lines that stably and constitutively expresses the SV40 large T antigen such as HEK293T. In brief, the reporter gene was digested from the plasmid pEGFP (BD Biosciences Clontech, Mountain View, CA) using restriction enzymes Hind III and Apa I and further cloned into pcDNA3.1. The construct $(5,7 \mathrm{~kb})$ was produced in $E$. coli and further purified using the Endotoxin-free (EF) Plasmid DNA Purification, NucleoBond ${ }^{\circledR}$ Xtra Midi EF (MachereyNagel, Düren, Germany) and resuspended in EF-water at $1 \mathrm{~g} / 1$.

Cell culture and microporation

Human Embryonic Kidney (HEK) 293T cells (ATCC-LGC Nr: CRL-11268; Middlesex, UK) were grown in adherence in $\mathrm{T}_{75}$ flasks with Dulbecco's Modified Eagle Medium (DMEM) high glucose $(4.5 \mathrm{~g} / \mathrm{l}), 10 \%$ fetal bovine serum (FBS), $1 \%$ penicillin/streptomycin $(100 \mu \mathrm{g} / \mathrm{ml})(\mathrm{Gibco}$, Invitrogen, La Jolla, CA) and were maintained at $37{ }^{\circ} \mathrm{C}$ and $5 \% \mathrm{CO}_{2}$-humidified atmosphere.

Sub-confluent cells were harvested and washed with DPBS. Cells were resuspended in a sacarose based buffer (SB-PBS: $250 \mathrm{mM}$ Sacarose and $1 \mathrm{mM} \mathrm{MgCl}_{2}$ in DPBS) or in the Resuspension Buffer (RB - provided by the equipment manufacturer) at a density of $\sim 2 \times 10^{5}$ cells/10 1 and incubated with plasmid DNA on ice. Microporation was accomplished within 20 min. maximum using a Microporator (MP-100) purchased from Digital Bio Technology (Seoul, South Korea) according to manufacturer's instructions. The ratio between cells and DNA ranged $710^{4}$ $2010^{4}$ cells/g and DNA amount is referred when appropriated. Afterwards cells were added to 1001 of pre-warmed medium without antibiotics and equally divided into 2 wells of a 24-well culture 
plates containing culture medium under the same conditions. Cells were incubated at $37{ }^{\circ} \mathrm{C}$ in a $5 \%$ $\mathrm{CO}_{2}$-humidified atmosphere, harvested after 24 hours using DPBS and analyzed.

Transfection efficiency, Cell Viability, Cell Recovery and Yield

Transfection efficiency was measured by flow cytometry using FACSCalibur equipment (BD Biosciences, San Jose, CA) and reported as percentage of GFP positive cells (GFP ${ }^{+}$cells). A laser excitation wavelength of $488 \mathrm{~nm}$ was used and experiments were conducted in $137 \mathrm{mM} \mathrm{NaCl}, 2.8$ $\mathrm{mM} \mathrm{KCl}$ solution as the sheath fluid. Results considered statistically representative had minimum 1000 events gated. Data were analyzed by CellQuest software (BD Biosciences, San Jose, CA).

The percentage of viable cells was estimated by trypan blue exclusion method. For each micro-electroporated sample $(m)$, Cell Recovery $(C R)$ was determined using the equation:

$$
C R(\%)_{m}=\frac{C A_{m}}{C A_{c}} \times 100
$$

where $C A$ is the number of cells alive and $c$ is the non-electroporated control. The yield of transfection $(Y)$ was calculated using the following equation:

$$
Y(\%)_{m}=\frac{G F P \oplus \times C A_{m}}{C T_{c}}
$$

where $C T$ is the number of total cells.

\section{Experimental Design}

Factorial designs are generally used to evaluate the effects of multiple independent factors and their degree of interaction. In this work we used a CCD to optimize gene delivery to HEK293T cells, using a microporation technology. The response (dependent variable) was the percentage of $\mathrm{GFP}^{+}$cells measured by flow cytometry. Accordingly, we evaluated the effects and interaction of 
four independent variables: electric pulse $\left(X_{1}\right)$, pulse width $\left(X_{2}\right)$, number of pulses $\left(X_{3}\right)$ and DNA amount $\left(X_{4}\right)$. Using a face centred star points design, three coded levels (low (-1); central (0) and high (+1)) were chosen according to previously obtained results (data not shown). The coded values of independent variables are given in Table 1.

(Table1)

This CCD design was used with the assistance of STATISTICA software (StatSoft, Tulsa, OK, USA) which has allowed estimation of a full quadratic model with the general description: $\mathrm{N}=$ $2^{k-p}+2 k+C_{0}$, where $\mathrm{N}$ is the number of experiments, $k$ is the number of independent variables $(k=$ 4), $p$ the fractionalization number (in a full design, $p=0)$ and $C_{0}$ is the number of central points $\left(C_{0}=\right.$ 4), required for curvature estimation (Barker 1985). Accordingly, a total of $28\left(2^{4-0}+24+4\right)$ different combinations (including four replicates of the central point each sighed the coded value 0) were chosen according to a CCD configuration for four independent variables.

\section{Results and Discussion}

The majority of reported studies regarding optimization of gene delivery efficiency to primary or established cell lines involve changing one variable while maintaining other formulation variables constant. Such time- and labor-consuming strategy may be ineffective because fails to consider potential interactions between variables. Alternatively, a statistical approach such as Central Composite Design involves a minimum number of experiments for a large number of factors. Additionally, Response Surface Methodology determines the optimum level of each factor by building a mathematical model. In the literature there are only few studies using the referred methodology aiming at optimizing non-viral gene delivery vectors and methodologies. The first reported study regarding this topic aimed to demonstrate the utility of Central Composite Design in modeling responses such as vector size, zeta potential and transfection efficiency of several non-viral gene delivery vectors (Birchall et al. 2001). Similarly other authors have verified the effect of several 
parameters and their interaction on physical stability of polyplexes (Gazori et al. 2009; Zhong et al. 2007). Regarding electroporation, and to our knowledge there is no reported study aiming at multivariate optimizing procedure for in vitro gene delivery in mammalian cells.

With our work we intended to show how the variables: electric pulse $\left(X_{1}\right)$, pulse width $\left(X_{2}\right)$, number of pulses $\left(X_{3}\right)$ and DNA amount $\left(X_{4}\right)$ affect gene delivery by microporation, and also inquire about their main interactions using a Central composite design (CCD). The number of $\mathrm{GFP}^{+}$cells, obtained by flow cytometry analysis was the dependent variable and the results are shown on Table 2. When using an electric pulse of $1500 \mathrm{~V}$ within $30 \mathrm{~ms}$ and/or 3 pulses, the recovered cells were not enough for flow cytometry measurement due to high cell mortality and so we considered as zero in the CCD.

(Table 2)

A second-order polynomial equation (Eq. 3) was used to express the $\mathrm{GFP}^{+}$cells percentage as a function of four independent variables. The quadratic effect of Electric pulse $\left(\mathrm{X}_{1}^{2}\right)$ and DNA amount $\left(\mathrm{X}_{4}^{2}\right)$ have shown the most pronounced effects on the number of $\mathrm{GFP}^{+}$cells.

$$
\begin{aligned}
& \mathrm{GFP}^{+} \text {cells }(\%)=36.1+2.8 \mathrm{X}_{1}-3.1 \mathrm{X}_{2}-1.8 \mathrm{X}_{3}+2.7 \mathrm{X}_{4}^{\tau} \quad 25.7 \mathrm{X}_{1}^{2}-9.0 \mathrm{X}_{2}^{\tau} \quad 4.4 \mathrm{X}_{3}^{2}+9.6 \mathrm{X}_{4}^{\tau} \quad 6.3 \mathrm{X}_{1} \mathrm{X}_{2} \\
& -3.6 \mathrm{X}_{1} \mathrm{X}_{3}+1.6 \mathrm{X}_{1} \mathrm{X}_{4}+3.4 \mathrm{X}_{2} \mathrm{X}_{3}^{\tilde{2}} \quad 1.7 \mathrm{X}_{2} \mathrm{X}_{4} \quad\left(\mathrm{R}^{2}=0.95\right)
\end{aligned}
$$

For each parameter estimator a test of significance was performed. Parameters with less than 95\% significance ( $p$-values above 0.05 ) were discarded and pooled into the error term (residual error). Accordingly, in the previous equation the parameter linear relation of $\mathrm{X}_{3}$ by $\mathrm{X}_{4}$ was not considered $(p=0.56)$. The model was further validated by analysis of variance (ANOVA), using a methodology previously presented by others (Martins et al. 2009), for determining which of the factors significantly affect the response variables in study $\left(\mathrm{GFP}^{+}\right.$cells), using a Fisher's statistical test $(F$-test $)$, The results are shown on Table 3.

(Table 3)

Data show that the model is statistically significant (for all the regression models, F-value > F-critical, $p$-value $<0.001)$ explaining $95 \%\left(\mathrm{R}^{2}=0.95\right)$ of the observed variance. There is no evidence of lack of fit at $95 \%$ confidence level, as determined by the ratio MS(LF)/MS(PE) (for all 
response variables, F-value $(\mathrm{LF})<\mathrm{F}$-critical and $\mathrm{p}$-value $>0.05)$, which means that the model explains the observed differences on the response variable. The relationships between independent and dependent variable can be easily visualized using RSM, where the obtained regression model was used to calculate the response surface for each response variable (Fig.1).

(Figure 1)

The effects of electric pulse and DNA amount on $\mathrm{GFP}^{+}$cells percentage are visualized from a threedimensional plot and a contour plot (Fig. 1A). A saddle-shaped surface plot was obtained and two maximal points were observed: one at higher and other at lower DNA amount, using an electric pulse of $\sim 1200 \mathrm{~V}$. Conversely, when using two pulses and $2 \mathrm{~g}$ of DNA the highest percentage of GFP cells are obtained at electric pulse and pulse width ranging from 1200-1300 V and 20-24 ms respectively (Fig. 1B). A similar peak-shaped response surface was obtained when plotting electric pulse and number of pulses at $20 \mathrm{~ms}$ and using $2 \mathrm{~g}$ of DNA, and again a higher number of GFP cells was obtained with $1200 \mathrm{~V}$ (Fig.1C). Optimal experimental conditions were selected from the response surfaces plots and higher values of $\mathrm{GFP}^{+}$cells ( 60\%) were obtained with 1200-1300 V, $20 \mathrm{~ms}$ of pulse width either using 1 or $3 \mathrm{~g}$ of DNA. The number of pulses (1-3) did not greatly affect the number of $\mathrm{GFP}^{+}$cells contrarily to some reported studies, although using different cell lines and electroporation equipments (Lin et al. 2009). It is well known that when cells are submitted to high electric pulses a major amount of DNA enter into the cells though concurrently an increase of cell death is observed (Ferreira et al. 2008). Several studies, using different cells, have shown that a way to circumvent this fact is by decreasing electric pulse and increasing the duration of pulse (pulse width) or within low voltages use more than one pulse (Cemazar et al. 2009). Higher transfection efficiency levels have also been obtained by increasing the DNA amount up to $60 \mathrm{~g}$ (corresponding to $\sim 210^{4}$ cells/g DNA) (Helledie et al. 2008) regardless lower DNA amounts are commonly employed. In fact, in our experiments with $3 \mathrm{~g}$ of DNA a similar ratio of cell/ $\mathrm{g}$ DNA $\left(\sim 710^{4}\right)$ was used. 
We further compared two different microporation buffers using different DNA amounts with the purpose of evaluating respective cellular viabilities, cell recoveries and overall yield. In this study we took advantage from the information retrieved from the previously shown CCD experiment and fixed the following microporation conditions: $1250 \mathrm{~V}, 20 \mathrm{~ms}$ and 1 pulse. One buffer was supplied by the equipment kit (RB - with unknown formulation) and the other was prepared in the laboratory with the formulation: $250 \mathrm{mM}$ Sacarose, $1 \mathrm{mM} \mathrm{MgCl} 2$ and $10 \mathrm{mM}$ Tris.HCl in DPBS (SB-PBS). The data shown in Figure 2 were obtained from three independent experiments.

(Figure 2) Using the equation model obtained by the experimental design (Eq.3) the predicted values for GFP+ cells when using SB-PBS under the referred conditions (in coded level: $\mathrm{X}_{1}=0.165 ; \mathrm{X}_{2}=0 ; \mathrm{X}_{3} \tilde{\sim}$ ) are $40 \%$ for $1 \mathrm{~g}$ DNA $\left(\mathrm{X}_{4} \tilde{\sim} 1\right)$ and $46 \%$ for $3 \mathrm{~g} \mathrm{DNA}\left(\mathrm{X}_{4}=1\right)$. In fact, from figure $2 \mathrm{~A}$ the obtained values were respectively $55 \%$ and $63 \%$, slightly higher than the predicted values, though as predicted both had similar values. On the other hand, when using RB the DNA amount is crucial. Lower amount of DNA displays higher number of $\mathrm{GFP}^{+}$cells (Fig 2B). As depicted from Fig. 2 the buffer prepared in the laboratory (SB-PBS) displayed higher cellular viabilities, and most importantly higher cellular recoveries and higher yields. Common to both buffers, as expected, is the fact that lower DNA amounts give rise to higher cell viabilities and recoveries which is mainly reflected in higher yield. Cellular viability using SB-PBS ranged from 70-90\% while with RB it achieved a maximum of $60 \%$ using a lower DNA amount. Cell recoveries and transfection yields obtained with RB were lower than $20 \%$ whereas with SB-PBS a maximum recovery of $50 \%$ and $30 \%$ yield were obtained. These results suggest that RB of unknown composition might have a higher conductivity than SB-PBS. In fact, previous reports have shown that the percentage of surviving cells increases with the decreasing medium conductivity (Ferreira et al. 2008) suggesting that electroporation buffer is other parameter that might be considered on electrotransfer optimization protocols. Even though each electroporation equipment has a specific buffer suggested by the supplier, some authors have recently reported promising results of gene delivery efficiencies using accessible buffers of known 
composition (Ferreira et al. 2008; Kang et al. 2009). Actually, in one experiment transfection efficiency obtained with RB was slightly higher than those obtained with SB-PBS because $78 \%$ of $\mathrm{GFP}^{+}$cells were obtained using $1 \mathrm{~g}$ of DNA. Contrarily, increasing DNA amount led to a clear reduction of transfection efficiency. This fact is in fair agreement with manufacturer instructions which suggests the use of $0.5 \mathrm{~g}$ of DNA per $1.510^{5}$ cells. It was recently reported that electroporation of cells in a capillary system gave rise to an enhancement of transfection rate and cell viability when compared to the cuvette system (Kim et al. 2008). In the conventional electroporation, using a cuvette, the reported cellular viabilities are generally below $70 \%$ and most importantly the cell recoveries are rarely mentioned, with the exception of few studies with primary cells (Aluigi et al. 2006; Ferreira et al. 2008). In this work we achieved cell viabilities up to $90 \%$ and cell recoveries near $50 \%$. Overall we were able to obtain a yield of transfection of $30 \%$.

We further evaluated the ability of microporated cells expressing GFP to form colonies under antibiotic selection. The plasmid used in this study had a resistance to Zeocine which was added to the cell culture $(250 \mathrm{~g} / \mathrm{ml})$ two days after microporation. After ten days, all non-transfected cells were dead and the first colonies were expanded maintaining around $95 \%$ of cells continuously expressing GFP. HEK293T cells can be used either for recombinant protein production or as a model to study a specific cellular feature or disease. For both applications gene delivery might be essential and in this study we presented an approach to optimize gene delivery to these cells.

\section{Conclusions}

In conclusion, this work illustrates the feasibility of microporation for the efficient delivery of plasmids into mammalian cells, using an easy to prepare buffer, whilst maintaining cell viability concurrently with high cell recoveries. Moreover, the usefulness of CCD for gene delivery optimization was demonstrated. This approach might be successfully applied to other transfection 
protocols for evaluating interactions between factors involved on transfection efficiency, therefore contributing to a faster monitoring and optimization.

\section{Acknowledgments}

We would like to thank Martins, S.M.A. for helpful discussions on the CCD analysis. This work was funded by Fundação para a Ciência e a Tecnologia through Post-doctoral grants awarded to C. Madeira (SFRH / BPD / 41755 / 2007) and to S. Ribeiro (SFRH / BPD / 41824 / 2007).

\section{References}

Aluigi M, Fogli M, Curti A, Isidori A, Gruppioni E, Chiodoni C, Colombo MP, Versura P, D'ErricoGrigioni A, Ferri E et al (2006) Nucleofection is an efficient nonviral transfection technique for human bone marrow-derived mesenchymal stem cells. Stem Cells 24(2):454-461

Barker TB (1985) Quality by Experimental Design. Dekker M (ed) New York

Birchall JC, Waterworth CA, Luscombe C, Parkins DA, Gumbleton M (2001) Statistical modelling of the formulation variables in non-viral gene delivery systems. J Drug Target 9(3):169-184

Cemazar M, Golzio M, Sersa G, Hojman P, Kranjc S, Mesojednik S, Rols MP, Teissie J (2009) Control by pulse parameters of DNA electrotransfer into solid tumors in mice. Gene Ther 16(5):635-644

Ferreira E, Potier E, Logeart-Avramoglou D, Salomskaite-Davalgiene S, Mir LM, Petite H (2008) Optimization of a gene electrotransfer method for mesenchymal stem cell transfection. Gene Ther 15(7):537-544

Gazori T, Khoshayand MR, Azizi E, Yazdizade P, Nomanie A, Haririan I (2009) Evaluation of Alginate/Chitosan nanoparticles as antisense delivery vector: Formulation, optimization and in vitro characterization. Carbohydr Polym 77(3):599-606

Helledie T, Nurcombe V, Cool SM (2008) A simple and reliable electroporation method for human bone marrow mesenchymal stem cells. Stem Cells Dev 17(4):837-848

Kang J, Ramu S, Lee S, Aguilar B, Ganesan SK, Yoo J, Kalra VK, Koh CJ, Hong YK (2009) Phosphate-buffered saline-based nucleofection of primary endothelial cells. Anal Biochem 386(2):251-255

Kim JA, Cho KC, Shin MS, Lee WG, Jung NC, Chung CI, Chang JK (2008) A novel electroporation method using a capillary and wire-type electrode. Biosens Bioelectron 23(9):1353-1360

Lee WG, Demirci U, Khademhosseini A (2009) Microscale electroporation: challenges and perspectives for clinical applications. Integr Biol 1(3):242-251

Lin W-Z, Lee SST, Cheung W-T (2009) Efficient expression of foreign genes in CHO DHFR cells by electroporation. Biol doi:10.1016/j.biologicals..03.003

Martins SAM, Prazeres DMF, Fonseca LP, Monteiro GA ( 2009) Application of central composite design for DNA hybridization onto magnetic microparticles. Anal Biochem 391(1): 17-23.

Pham PL, Kamen A, Durocher Y (2006) Large-scale Transfection of mammalian cells for the fast production of recombinant protein. Mol Biotechnol 34(2):225-237 
Wurm FM, Baldi L, Girard JP, Lindell J, Grosjean F, Muller N, Jacquet R, Wright J, Mason A, Hacker D et al (2003) Transient gene expression: A novel mammalian cell-based technology for recombinant protein production - A historical and technical perspective. Anim Cell Technol: Basic \& Appl Asp 13:83-88

Zhong ZR, Liu J, Deng Y, Zhang ZR, Song QG, Wei YX, He Q (2007) Preparation and characterization of a novel nonviral gene transfer system: Procationic-liposome-protamineDNA complexes. Drug Deliv 14(3):177-183 
Table 1 Uncoded and coded levels of the independent variables.

\begin{tabular}{lcccc}
\hline \multirow{2}{*}{ Independent Variables } & \multicolumn{3}{c}{ Coded levels } \\
\cline { 3 - 5 } & & -1 & 0 & +1 \\
\hline $\mathrm{X}_{1}$ & Electric pulse $(\mathrm{V})$ & 900 & 1200 & 1500 \\
$\mathrm{X}_{2}$ & Pulse width $(\mathrm{ms})$ & 10 & 20 & 30 \\
$\mathrm{X}_{3}$ & Pulse number & 1 & 2 & 3 \\
$\mathrm{X}_{4}$ & DNA amount $(\mathrm{g})$ & 1 & 2 & 3 \\
\hline
\end{tabular}


Table 2 Experimental results of the dependent variable $\left(\mathrm{GFP}^{+}\right.$cells $\left.(\%)\right)$ after microporation of HEK293T using a CCD design setup.

\begin{tabular}{cccccc}
\hline & \multicolumn{3}{c}{ Independent variables } & $\begin{array}{c}\text { Dependent } \\
\text { variable }\end{array}$ \\
\cline { 2 - 6 } & $\mathrm{X}_{1}{ }^{*}$ & $\mathrm{X}_{2}{ }^{*}$ & $\mathrm{X}_{3}{ }^{*}$ & $\mathrm{X}_{4}{ }^{*}$ & $\mathrm{GFP}^{+}$cells $(\%)$ \\
\hline 1 & -1 & -1 & -1 & -1 & 0.4 \\
2 & 1 & -1 & -1 & 1 & 26.1 \\
3 & -1 & 1 & -1 & -1 & 2.2 \\
4 & 1 & 1 & -1 & -1 & 0.0 \\
5 & -1 & -1 & 1 & -1 & 0.9 \\
6 & 1 & -1 & 1 & -1 & 0.0 \\
7 & -1 & 1 & 1 & -1 & 10.3 \\
8 & 1 & 1 & 1 & -1 & 0.0 \\
9 & -1 & -1 & -1 & 1 & 0.5 \\
10 & 1 & -1 & -1 & 1 & 35.2 \\
11 & -1 & 1 & -1 & 1 & 4.2 \\
12 & 1 & 1 & -1 & 1 & 0.0 \\
13 & -1 & -1 & 1 & 1 & 1.9 \\
14 & 1 & -1 & 1 & 1 & 17.4 \\
15 & -1 & 1 & 1 & 1 & 8.3 \\
16 & 1 & 1 & 1 & 1 & 0.0 \\
17 & -1 & 0 & 0 & 0 & 9.2 \\
18 & 1 & 0 & 0 & 0 & 10.1 \\
19 & 0 & -1 & 0 & 0 & 25.0 \\
20 & 0 & 1 & 0 & 0 & 27.6 \\
21 & 0 & 0 & -1 & 0 & 32.6 \\
22 & 0 & 0 & 1 & 0 & 29.3 \\
23 & 0 & 0 & 0 & -1 & 34.7 \\
24 & 0 & 0 & 0 & 1 & 55.1 \\
25 & 0 & 0 & 0 & 0 & 38.6 \\
26 & 0 & 0 & 0 & 0 & 39.2 \\
27 & 0 & 0 & 0 & 0 & 35.0 \\
28 & 0 & 0 & 0 & 0 & 37.0 \\
& & & & & \\
\hline
\end{tabular}

*Uncoded levels of independent variables $\left(\mathrm{X}_{1}=\right.$ electric pulse; $\mathrm{X}_{2}=$ pulse width; $\mathrm{X}_{3}=$ pulse number; $\mathrm{X}_{4}=\mathrm{DNA}$ amount $)$ are presented in Table 1. 
Table 3 ANOVA for the reduced quadratic model (Eq. 3) that predicts the response variable GFP ${ }^{+}$ cells, as a function of the independent variables after microporation.

\begin{tabular}{ccccccc}
\hline \multicolumn{1}{c}{ Source } & $S S$ & $d f$ & MS & F-value & F-critical & p-value \\
\hline Regression & 7167 & 13 & 551 & 23 & 3 & $<0.001$ \\
Residual & 335 & 14 & 24 & & & \\
Lack of fit & & & & & & \\
(LF) & 323 & 11 & 29 & 8 & 9 & 0.06 \\
$\begin{array}{r}\text { Pure Error } \\
\text { (PE) }\end{array}$ & 12 & 3 & 4 & & & \\
Total & 7501 & 27 & & & & \\
\hline
\end{tabular}


Fig. 1 Predicted response surface plots relating the percentage of $\mathrm{GFP}^{+}$cells with two independent variables while the other two are fixed. The fixed variables were: 2 pulses and $20 \mathrm{~ms}$ of pulse width (A); $2 \mu \mathrm{g}$ of DNA and 2 pulses (B) and $20 \mathrm{~ms}$ of pulse width and $2 \mu \mathrm{g}$ of DNA (C). The 2-D and 3-D figures are predicted by the quadratic model equation (Eq. 3).

Fig. 2 Effect of microporation buffers SB-PBS (A) and RB (B) on gene delivery to HEK293T cells with different amounts of plasmid DNA ( $1 \mathrm{~g}$ in black and $3 \mathrm{~g}$ in white) at $1250 \mathrm{~V}, 20 \mathrm{~ms}$ and 1 pulse. The number of $\mathrm{GFP}^{+}$cells, cell viability, cell recovery and yield of transfection were obtained from three independent experiments (mean standard deviation). 
Figure 1
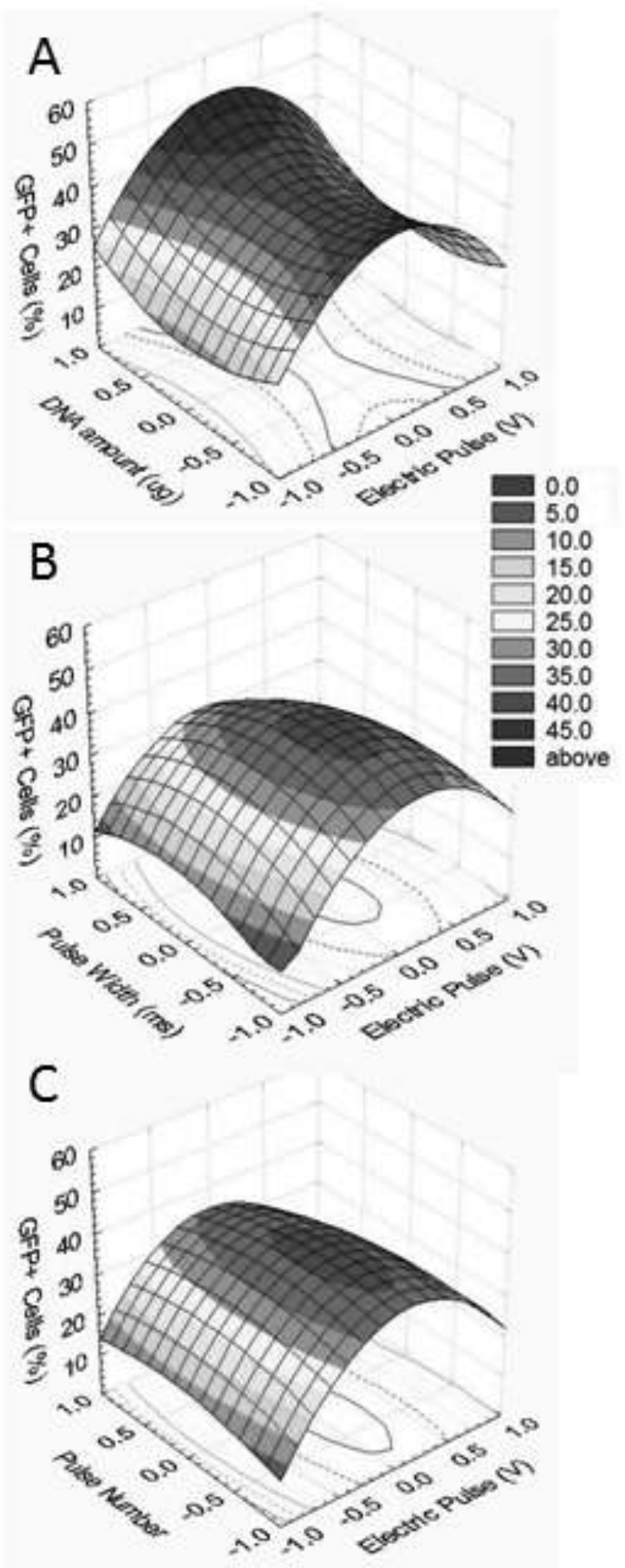
Figure 2
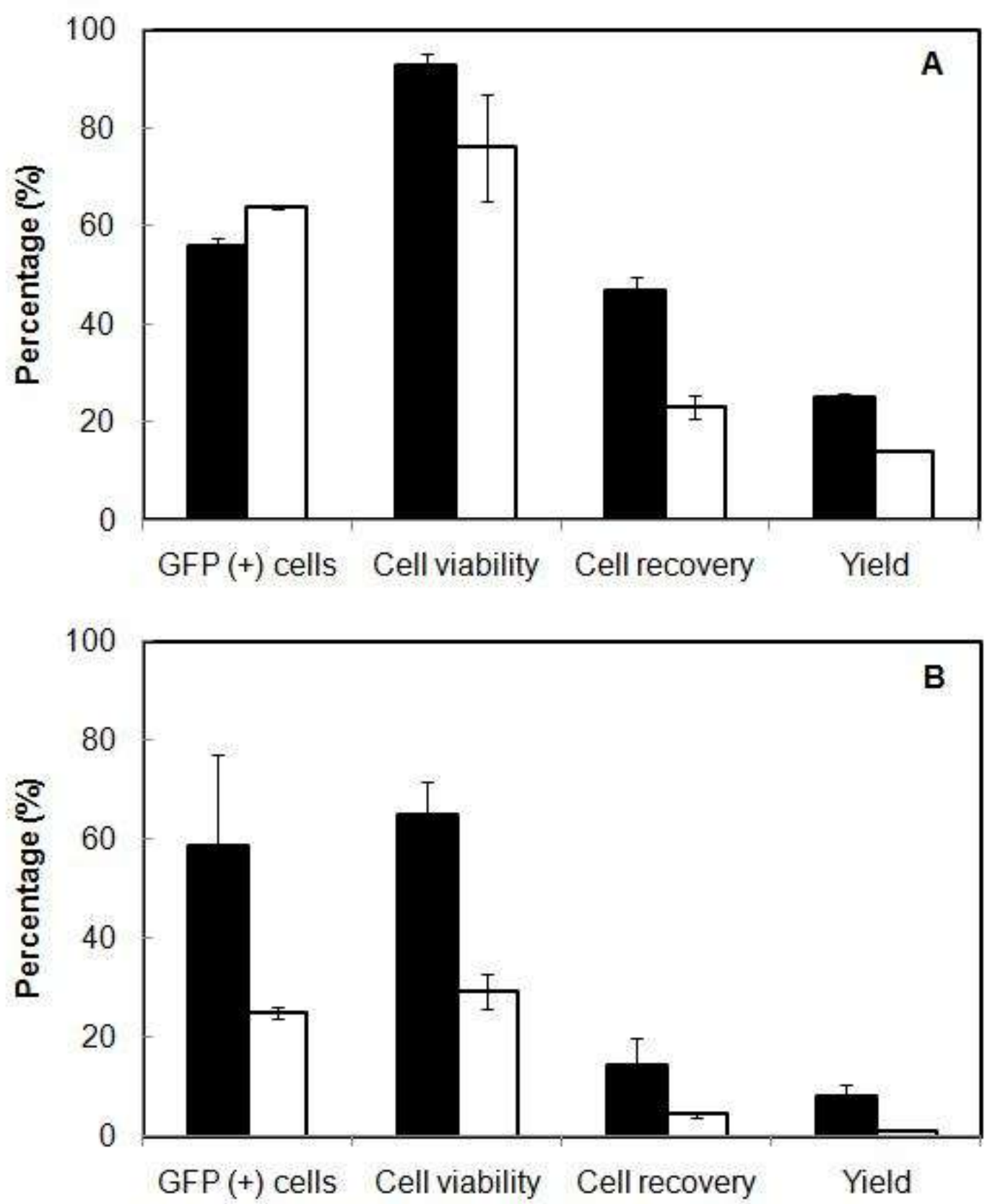